\title{
Anesthetic Activities of Scheduled Surgery at CHU Gabriel Touré
}

\author{
Mangané Moustapha ${ }^{*}$, Almeimoune Abdoul Hamidou1, Diop Thierno Madane1, \\ Soumaré Alfousseini, Koita Siriman ${ }^{3}$, Sanogo Dramane1, Gamby Amadou${ }^{1}$, Siadaly Babaya ${ }^{1}$, \\ Dembelé Aladji Seydou², Diango Djibo Mahamane ${ }^{1}$
}

\author{
${ }^{1}$ Department of Anesthesiology and ICU, Hôpital Gabriel Touré, Bamako, Mali \\ ${ }^{2}$ Department of Anesthesiology, Hôpital IOTA, Bamako, Mali \\ ${ }^{3}$ Department of Anesthesiology and ICU, Hôpital Mère-Enfant, Bamako, Mali \\ Email: *mbayemangane@gmail.com
}

How to cite this paper: Moustapha, M., Hamidou, A.A., Madane, D.T., Alfousseini, S., Siriman, K., Dramane, S., Amadou, G., Babaya, S., Seydou, D.A. and Mahamane, D.D. (2021) Anesthetic Activities of Scheduled Surgery at CHU Gabriel Touré. Open Journal of Anesthesiology, 11, 164-174. https://doi.org/10.4236/ojanes.2021.115016

Received: March 28, 2021

Accepted: May 28, 2021

Published: May 31, 2021

Copyright $\odot 2021$ by author(s) and Scientific Research Publishing Inc. This work is licensed under the Creative Commons Attribution International License (CC BY 4.0).

http://creativecommons.org/licenses/by/4.0/

\begin{abstract}
Concept: We opted for this study because the hospital unit Gabriel Touré was renovated with 7 surgical specialties. Our study was the very last study before the advent of coronavirus disease 2019 (COVID 19). Goal: Evaluate the anesthetic activities of the planned surgery at the University Hospital Center CHU Gabriel Touré. Method and Material: This was a descriptive prospective study carried out in the cold operating theater of the CHU Gabriel Touré from January to December 2018. It focused on all patients operated on for regulated surgery and who had benefited from anesthesia. Our data was entered and analyzed on SPSS 25 software. Word processing performed on Microsoft WORD ${ }^{\circledR} 2016$ and graphics on Microsoft EXCEL ${ }^{\circledR} 2016$. Results: During the study period 1700 patients were operated on in the operating room for scheduled surgery. The age range of 0 to 5 years accounted for (14.8\%). The average age was 6.64 years; male predominance $(52.6 \%)$ of operated patients with a sex ratio of 1.1. A history of general anesthesia was found in $62.1 \%$. The classification of the American Anesthesia Society (ASA) ASA1 class represented $92.7 \%$. Tonsillitis was the most common operative diagnosis (9.5\%). Hernia cures and eventrations were the most common surgical technique (11.8\%). General anesthesia was achieved in $65.3 \%$ of patients. Hypotension was the most common adverse event in the operating room, $44.5 \%$. The intraoperative mortality was $0.11 \%$. Conclusion: Our study covered the entire population anesthetized. It provided an update on the practice of anesthesia in the intensive care unit anesthesia. General anesthesia was the most used technique; a predominance of cardiovascular adverse events, occurring more often in induction and mainly favorable outcome with mortality intraoperative $0.11 \%$. A growing presence of MAR and DES who had per-
\end{abstract}


formed more than $30 \%$ of anesthesia.

\section{Keywords}

Anesthetic Activities, CHU Gabriel Touré, Bamako

\section{Introduction}

The anesthesia allows the operation to proceed smoothly with pain relief, patient immobility and neurovegetative protection [1]. Nowadays, in well-off countries, it allows the efficient care of fragile patients for increasingly heavy interventions. Developing countries, and more particularly those of sub-Saharan Africa remain outside these advances, with a very high perioperative mortality, in connection with multiple shortages including the lack of qualified personnel, the obsolescence of equipment and the frequent shortage of essential drugs [2] [3] [4]. However, it must be recognized that a great deal of effort has been made in Mali to follow in the footsteps of progress in the field of anesthesia. Several studies have been carried out on the evaluation of the quality of anesthetic care at the CHU Gabriel Touré [5]; as well as the reports of anesthetic activities [6] at the Pasteur Bamako clinic. In order to improve the quality of the activities and to have recent statistical data of the activity provided by the cold operating room of the $\mathrm{CHU} \mathrm{Ga}$ briel Touré, the present work was initiated. It could represent a frame of reference making it possible to periodically gauge the evolution of the practice of anesthesia over time. Our objective was to evaluate the anesthetic activities of the planned surgery at CHU Gabriel Touré.

\section{Methodology}

This work is a descriptive prospective study carried out in the cold operating room of the CHU Gabriel Touré from January to December 2018. It focused on all the patients operated on in the operating room for controlled surgery and having benefited from anesthesia. Any patient taken in the operating room for emergency surgery was excluded from the study. Planned surgery was performed Monday through Thursday in the cold operating room. The weekly cold room operating program is established every Thursday. We used as support the patient's medical file and the investigation sheet carried out in the operating room department. The parameters studied were socio-demographic data, history, preoperative diagnosis, type of surgery, data from the pre-anesthetic consultation, the most used anesthetic products, incidents and accidents and times of occurrence, surveillance in the SSPI and post-operative complications. Our data was entered and analyzed on SPSS 25 software. Word processing was performed on Microsoft WORD $^{\circledR} 2016$ and graphics on Microsoft EXCEL ${ }^{\circledR} 2016$.

\section{Results}

During the study period 1700 patients were taken to the operating room for 
scheduled surgery and who received anesthesia. The age range of 0 to 5 years was the most represented with $14.8 \%(\mathrm{n}=252)$ (Figure 1$)$. The mean age was 6.64 years ranging from 07 days to 82 years and a standard deviation of 4.12; male predominance $52.6 \%(\mathrm{n}=894)$ a sex ratio of 1.1 of the operated patients with a sex ratio of 1.1.

Patient history: Arterial hypertension (HTA) in 45.7\% ( $\mathrm{n}=78)$ (Table 1); 77\% $(\mathrm{n}=1309)$ had never been operated on and 93.6\% $(\mathrm{n}=1592)$ (Table 1) had never received a transfusion. In our study $62.1 \%(\mathrm{n}=238)$ (Table 1$)$ of patients had a history of general anesthesia. The majority of our patients were smokers 87.7\% ( $\mathrm{n}=78)$. The pre-anesthetic consultations (CPA) were mainly carried out by resuscitator anesthetist (MAR) $(96.6 \%)(\mathrm{n}=1643)$. The ASA1 class represented 92.7\% $(\mathrm{n}=1576)$ (Table 2$)$ of cases.

General surgery was the surgical specialty performing the most procedures with $23.1 \%(n=393)$ (Table 3). Tonsillitis was the most common operative diagnosis at $9.5 \%(\mathrm{n}=161)$ (Table 4$)$. Hernia cures and eventrations were the most common surgical technique $11.8 \%(\mathrm{n}=200)($ Table 5$)$.

General anesthesia (GA) was achieved in $65.3 \%(n=1110)($ Table 6$)$ of patients. Ketamine, the combination Celocurine + Norcuron, Isoflurane were the most used in GA induction, respectively $67.6 \%(\mathrm{n}=790) ; 68.8 \%(\mathrm{n}=757)$ and $92.4 \%(\mathrm{n}=1079)$. Fentanyl was used the most for analgesia in our patients $100 \%$ $(\mathrm{n}=1700)$. Our patients received the combination Bupivacaine $0.5 \%+$ Morphine by ALR induction $96.6 \%(\mathrm{n}=536)$ cases. The IADEs performed $69.9 \%(\mathrm{n}$ $=1188$ ) of the anesthesias.

Hypotension was the most common adverse event occurring in the operating room 44.5\% $(\mathrm{n}=196)$ (Table 7). Adverse effects occurred during induction $55.1 \%(n=242)$ of cases (Table 8). The intraoperative mortality was $0.11 \%(n=$ 2). Most of the operated patients went through a Post-intervention surveillance

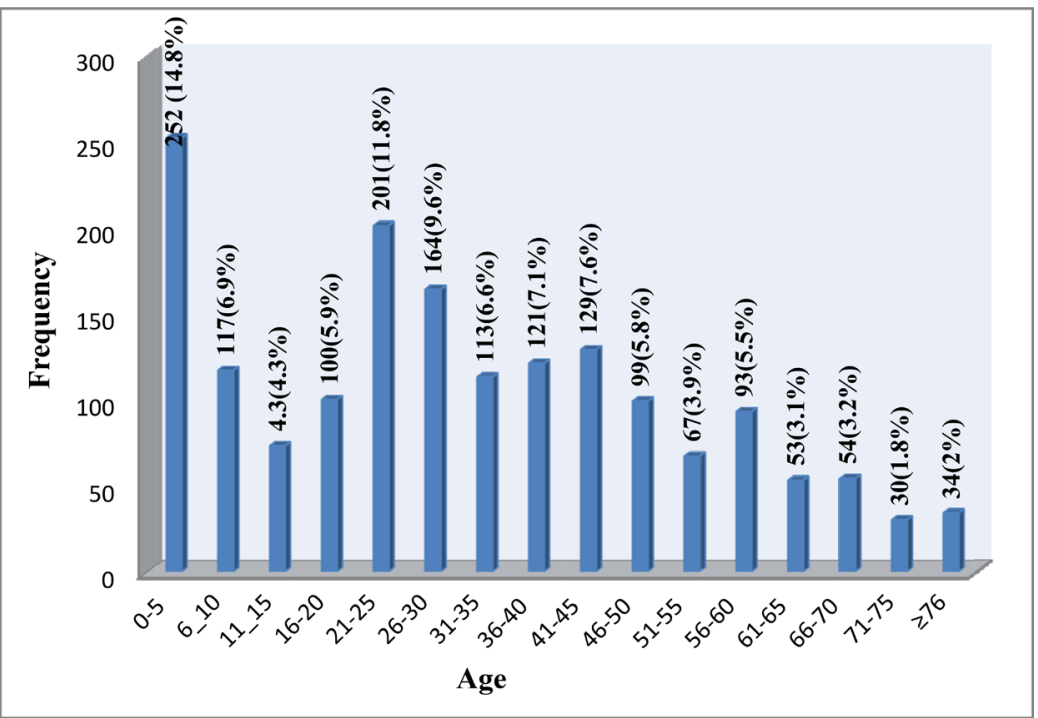

Figure 1. Distribution of patients according to age; the age range of 0 to 5 years was the most represented with $14.8 \%$ (252). 
Table 1. Distribution of patients according to history.

\begin{tabular}{|c|c|c|c|}
\hline & History & Number & Percentage \\
\hline \multirow[t]{11}{*}{ Medical } & HTA & 78 & 45.7 \\
\hline & Diabetes & 13 & 7.6 \\
\hline & Stroke & 1 & 0.1 \\
\hline & Obesity/Overload & 5 & 3.0 \\
\hline & Epilepsy & 3 & 1.8 \\
\hline & Allergy & 28 & 16.4 \\
\hline & Asthma & 21 & 12.3 \\
\hline & COPD & 2 & 1.2 \\
\hline & Hypertension + Diabetes & 14 & 8.2 \\
\hline & Sickle cell disease & 4 & 2.3 \\
\hline & HIV & 1 & 0.1 \\
\hline \multirow[t]{2}{*}{ Surgical } & Already operated & 391 & 23.0 \\
\hline & Never operated & 1309 & 77.0 \\
\hline \multirow[t]{4}{*}{ Anesthetics } & General anaesthesia & 238 & 62.1 \\
\hline & Spinal anesthesia & 120 & 31.3 \\
\hline & Epidural anesthesia & 13 & 3.4 \\
\hline & Local anesthesia & 12 & 3.2 \\
\hline \multirow[t]{2}{*}{ Transfusionists } & Already transfused & 108 & 6.4 \\
\hline & Never transfused & 1592 & 93.6 \\
\hline \multirow[t]{3}{*}{ Obstetricians } & Primiparous & 57 & 11.3 \\
\hline & $2^{\text {nd }}$ to $5^{\text {th }}$ Gesture & 263 & 52.0 \\
\hline & Multipare & 186 & 36.7 \\
\hline
\end{tabular}

CVA: Cerebral Vascular Accident; COPD: Chronic Obstructive Pulmonary Disease; HIV: Human Immunodeficiency Virus; SA: Spinal anesthesia; EA: Epidural anesthesia; LA: Local anesthesia.

Table 2. Distribution of patients according to ASA class.

\begin{tabular}{ccc}
\hline ASA Classification & Frequency & Percentage \\
\hline ASA 1 & 1576 & 92.7 \\
ASA 2 & 109 & 6.4 \\
ASA 3 & 14 & 0.8 \\
ASA 4 & 1 & 0.1 \\
Total & 1700 & 100.0 \\
\hline
\end{tabular}

ASA: American Anesthesia Society.

Table 3. Distribution of patients according to the department of origin.

\begin{tabular}{ccc}
\hline Surgical specialty & Frequency & Percentage \\
\hline Gyneco-obstetrics & 197 & 11.6 \\
Neurosurgery & 124 & 7.3 \\
General surgery & 393 & 23.1 \\
Trauma & 199 & 11.7 \\
otolaryngology & 316 & 18.6 \\
Urology & 246 & 14.5 \\
Pediatric surgery & 225 & 13.2 \\
Total & 1700 & 100.0 \\
\hline
\end{tabular}

ORL: Otorhinolaryngology. 
Table 4. Distribution of patients according to operative diagnosis.

\begin{tabular}{|c|c|c|}
\hline Operative diagnosis & Frequency & Percent \\
\hline Upper limb fracture & 38 & 2.2 \\
\hline Goitre & 70 & 4.1 \\
\hline Bladder lithiasis & 125 & 7.4 \\
\hline Hydrocephalus & 23 & 1.4 \\
\hline Digestive tumor & 74 & 4.4 \\
\hline Otitis & 50 & 2.9 \\
\hline Burn & 31 & 1.8 \\
\hline Cryptorchidism & 24 & 1.4 \\
\hline Breast tumor & 61 & 3.6 \\
\hline Anal fistula & 31 & 1.8 \\
\hline Lower limb fracture & 124 & 7.3 \\
\hline Vertebral fracture & 55 & 3.2 \\
\hline Osteomyelitis & 14 & 0.8 \\
\hline Prolapse & 46 & 2.7 \\
\hline Scarred uterus & 21 & 1.2 \\
\hline Cyst & 87 & 5.1 \\
\hline Papilloma & 23 & 1.4 \\
\hline Ostomy & 70 & 4.1 \\
\hline Brain tumor & 17 & 1.0 \\
\hline Kidney tumor & 37 & 2.2 \\
\hline Hirschsprung disease & 20 & 1.2 \\
\hline Prostate adenoma & 90 & 5.3 \\
\hline Brain embarrassment fracture & 2 & 0.1 \\
\hline Spina bifida & 13 & 0.8 \\
\hline Collar neo & 28 & 1.6 \\
\hline Postoperative eventration & 26 & 1.5 \\
\hline Genital tumor & 17 & 1.0 \\
\hline Pseudarthrosis & 27 & 1.6 \\
\hline Scarring bridle & 18 & 1.1 \\
\hline Anorectal malformation & 15 & 0.9 \\
\hline Bladder exstrophy & 3 & 0.2 \\
\hline Hemorrhoidal Diseases & 12 & 0.7 \\
\hline Hernia & 134 & 7.9 \\
\hline Dysphonia & 27 & 1.6 \\
\hline Tonsillitis & 161 & 9.5 \\
\hline Uterine myoma & 8,6 & 5 \\
\hline Total & 1700 & 100.0 \\
\hline
\end{tabular}


Table 5. Distribution of patients according to the surgical technique.

\begin{tabular}{|c|c|c|}
\hline Surgical technique & Frequency & Percent \\
\hline Tonsillectomy & 162 & 9.5 \\
\hline Resection & 143 & 8.4 \\
\hline Coeliosurgery & 23 & 1.4 \\
\hline Brushing & 35 & 2.1 \\
\hline Mastectomy & 56 & 3.3 \\
\hline Uterine myomectomy & 54 & 3.2 \\
\hline Prosthesis & 18 & 1.1 \\
\hline Nodulectomy & 8 & 0.5 \\
\hline Osteosynthesis & 89 & 5.2 \\
\hline Thyroidectomy & 69 & 4.1 \\
\hline Adenectomy & 91 & 5.4 \\
\hline Urethroplasty & 54 & 3.2 \\
\hline Cesarean & 22 & 1.3 \\
\hline Laryngoscopy & 27 & 1.6 \\
\hline Fistulectomy & 29 & 1.7 \\
\hline Restoration of digestive continuity & 70 & 4.1 \\
\hline Tympanoplasty & 43 & 2.5 \\
\hline Orchidopexy & 18 & 1.1 \\
\hline Sequestromia & 14 & 0.8 \\
\hline Colo-anal lowering & 19 & 1.1 \\
\hline Lifting embarrassment & 2 & 0.2 \\
\hline Material removal & 34 & 2.0 \\
\hline Laminectomy + internal fixation & 33 & 1.9 \\
\hline Ventriculoperitoneal shunt & 28 & 1.7 \\
\hline Gastrectomy & 30 & 1.8 \\
\hline Biopsy & 14 & 0.8 \\
\hline Release & 20 & 1.2 \\
\hline Anoplasty & 15 & 0.9 \\
\hline Hemorrhoidectomy & 11 & 0.6 \\
\hline Panendoscopy & 27 & 1.6 \\
\hline Nephrolithotomy & 42 & 2.5 \\
\hline External fixator & 9 & 0.5 \\
\hline Nephrectomy & 22 & 1.3 \\
\hline Screw plate & 41 & 2.4 \\
\hline Autograft & 32 & 1.9 \\
\hline Hysterectomy & 96 & 5.7 \\
\hline Cure hernia, eventration & 200 & 11.8 \\
\hline Total & 1700 & 100.0 \\
\hline
\end{tabular}


Table 6. Common anesthetic technique used.

\begin{tabular}{ccc}
\hline Anesthetic technique & Frequency & Percentage \\
\hline General anaesthesia & 1110 & 65.3 \\
Spinal anesthesia & 568 & 33.4 \\
Epidural anesthesia & 5 & 0.3 \\
Local anesthesia & 17 & 1.0 \\
Total & 1700 & 100.0 \\
\hline
\end{tabular}

Table 7. Main types of adverse events observed.

\begin{tabular}{ccc}
\hline Adverse events AE & Frequency & Percentage \\
\hline Hypotension & 196 & 44.5 \\
Bleeding & 88 & 20 \\
Cardiac arrest & 3 & 0.7 \\
Fail PL & 37 & 8.4 \\
Bradycardia & 23 & 5.2 \\
Hypotension + bleeding & 93 & 21.1 \\
Total & 440 & 100.0
\end{tabular}

UE: Adverse Event; LP: lumbar puncture.

Table 8. Distribution of AEs according to time of onset.

\begin{tabular}{ccc}
\hline Time of occurrence & Frequency & Percent \\
\hline Induction & 242 & 55.1 \\
Incision & 13 & 2.9 \\
Maintenance & 185 & 42.0 \\
Total & 440 & 100.0 \\
\hline
\end{tabular}

room $70.6 \%(n=1201)$.

\section{Discussion}

The difficulties encountered in our study were mainly due to the fact that the anesthetic files were not correctly completed intraoperatively.

We were limited by anesthesiologist's reluctance to report minor adverse events with spontaneously favorable outcome that occurred during anesthesia and incomplete anesthesia records.

In our study, anesthesiologists' reluctance to report minor adverse events during anesthesia comparable to that found by Hicham, K., et al. where the spontaneous development in $62 \%$ of patients who presented an adverse event and $38 \%$ were transferred to intensive care [7].

In our study we found a male predominance of $52.6 \%$ against $47.4 \%$ of women. Results were different from that of Diango, D. at the Gabriel Touré University Hospital in Bamako who had a sex ratio of 2.48 in favor of men [8]. 
The 0 to 5 years age group was the most represented in our study $14.8 \%$ this could be explained by the fact of the high activity of pediatric surgery and ENT service. The mean age was 6.64 years with extremes ranging from 07 days to 82 years and a standard deviation of 4.12. Results superior to that of Samake, B. at the Gabriel Touré University Hospital in Bamako who had a mean age of 2 years with the extremes ranging from 16 days to 12 years and a standard deviation of 2.93 [9].

Only $10 \%$ of our patients had a medical history contrary to that of Samake B at the Gabriel Touré University Hospital in Bamako where $66.4 \%$ of patients had no history [10]. They were observed in $21.77 \%$ of patients admitted to the operating room after consultation with anesthesia. At $79.22 \%$, general anesthesia was the most common anesthetic history.

Class ASA I American Society of Anesthesia was observed in $92.7 \%$ of cases observation similar to that of Belkrezia [11].

General anesthesia was offered in $65.3 \%$ of patients versus $33.4 \%$ for loco regional anesthesia.

In our series, $69.9 \%(\mathrm{n}=1188)$ of the interventions were performed by IADE; $14.2 \%(\mathrm{n}=241)$ by MAR and $15.9 \%(\mathrm{n}=271)$ by DES (Special Study Diploma) contrary to the proportions found by Dembele, A.S. et al. Pasteur medical-surgical and intensive care clinic in Bamakowith $74.6 \%$ of anesthesias were performedby MAR and $25.4 \%$ by IADE [6].

General anesthesia accounted for $65.3 \%$ versus $34.7 \%$ ALR of anesthesia performed. Observations were similar to that of Samake, B., et al. at the Gabriel Touré University Hospital in Bamako [10]. This primacy of general anesthesia is a constant in both African [13] [14] [11] [15] and international literature [16].

The combination Bupivacaine 0.5\% + Morphine 96.6\% was the most used in RA; followed by the combination of Xylocaine $2 \%+$ Bupivacaine $0.5 \%+$ Morphine 1.3\% for ODA; and Xylocaine 2\% for local anesthesia.

During general anesthesia, the narcotic combination + curare was the most used protocol in the majority of cases. Overall, ketamine was the most widely used anesthetic agent with $66.7 \%$ followed by Celocurine + Norcuron $68.8 \%$. Our observation was different from that of Konan Kouassi, J.E. who had used ketamine as the most widely used anesthesia agent (53\%) and vecuronium had been used (100\%) [17].

Fentanyl was the analgesic used in all of our patients during induction in the majority of patients. Same remark made by Essola, L., et al., who used Fentanyl as an analgesic in all of their patients [18].

Visceral surgery was the most frequent in our study $23.1 \%$ of interventions. Proportions similar to that of Belkrezia [11]. This could be explained by the visceral surgery done at the CHU Gabriel Touré is a general surgical service; it therefore presents a wide variety of surgical indications, thus performing obstetric, otorhinolaryngology and urological surgery.

In our study, tonsillitis represented $9.5 \%$ of operative diagnoses, a result lower 
than that of ABHE CM at Cocody University Hospital in Abidjan [19] where obstructed labor was the most represented operative diagnosis at $31.9 \%(\mathrm{n}=$ 258).

The hernia cure, eventration was the surgical procedure the most represented in our study with $11.8 \%$ result lower than that of the study of N'diaye, P.I. [12] at the CHU A Le Dantec of Dakar which had found the cureinguinal hernia (60\%) during his study.

Most of the anesthesias (55.3\%), lasted for more than one hour. This observation is different from that of Dembele, A.S. who found $57.3 \%$ of patients had an intervention period of less than 60 minutes [6].

In our series, $25.8 \%$ of patients had experienced an adverse reaction during the surgery. Arterial hypotension predominated, it was found (44.5\%) of cases. These events occurred more often during induction (55.1\%) of cases. Filling was the most common solution. Proportions were higher than those found by Dembele, A.S. where $14.5 \%$ of patients had presented an adverse event during surgery.

Isolated arterial hypotension was predominant (6.8\%). All of these patients developed it. Vasopressors have been used the most in the management of the hypotension, followed by filling fluids including macromolecules [6]. Our series observed only 3 cases of cardiac arrest.

The adverse events had a favorable outcome in the majority of cases. We recorded $0.11 \%$ of intraoperative deaths. This rate is close to that found by Tiret and Col [20] in France 0.19\%. On the other hand, Dembele, A.S., et al. at the Polyclinic Pasteur in Bamako [6], in their series the intraoperative mortality was $0.6 \%$. This could be due to the fact that our study only looked at regulated surgery and the majority of the anesthesia population was relatively well doing ASA1 especially. And also heavy surgeries and poor prognosis were infrequent.

\section{Conclusions}

Our study covered the entire population anesthetized in the cold block at $\mathrm{CHU}$ Gabriel Touré from January to December 2018. It provided an update on the practice of anesthesia in the intensive care unit anesthesia.

General anesthesia was the most used technique; a predominance of cardiovascular adverse events, occurring more often in induction and mainly favorable outcome with mortality intraoperative $0.11 \%$. A growing presence of MAR and DES who had performed more than $30 \%$ of anesthesia.

\section{Conflicts of Interest}

The authors declare no conflicts of interest regarding the publication of this paper.

\section{References}

[1] Lokossou, T., Zoumenou, E., Secka, G., Ouro Bang'na, F., Le Polain de Waroux, B., 
Veyckemans, F., Baele, P. and Chobli M. (2007) Anesthesia in French-Speaking Sub-Saharan Africa: An Overview. Acta Anaesthesiologica Belgica, 58, 197-209.

[2] Ouro Bang'na Maman, A.F., Tomta, K., Kangni, N., et al. (2008) Assessment of the Anesthesia Technical Platform in Togo: Multi-Center Survey Covering 23 Health Facilities. Black African Medicine, 55.

[3] Chobli, M., Mignonsin, D., Mambana, C., Hage, S. and Ahouangbevi, S. (1996) Equipment Levels of Anesthesia-Intensive Care Services in French-Speaking Black Africa. African Journal of Anesthesiology and Emergency Medicine, 20, 33-36.

[4] Yapobi, Y. (2008) Anesthetic Practice in French-Speaking Black African Countries. RAMUR, XIII, 24.

[5] Diango, M.D. (2013) Assessment of the Quality of Anesthetic Practices in Surgical Emergencies at the CHU Gabriel Touré. RAMUR, 18, Article No. 4.

[6] Dembele, A.S. (2013) Anesthetic Activities at the Pasteur Medico-Surgical and Intensive Care Clinic in Bamako. RAMUR, 18, 44-49.

[7] Hicham, K., et al. (2016) Intraoperative Adverse Events: Critical Reading of the Operating Room Register of the Moulay Ismail Meknes Military Hospital. The Pan African Medical Journal, 24, Article No. 178.

[8] Diango, D. (2013) Incidents and Anesthetic Accidents in Orthopedic and Trauma Surgery at the CHU Gabriel Touré in Bamako. $S A R A F, 18$, Article No. 2.

[9] Samake, B. (2009) Adverse Events of Anesthesia in Programmed Pediatric Surgery at the Gabriel Touré Hospital. Mali Medical, XXIV, Article No. 1.

[10] Samake, B. (2018) Adverse Events during Anesthesia for Digestive Surgery Planned at the CHU Gabriel Touré. Mali Medical, XXXIII, Article No. 4.

[11] Belkrezia, R., Kabbaj, S., Ismaili, H. and Maozouzin, W. (2002) Survey on the Practice of Anesthesia in Morocco. Annales Françaises d Anesthésie et de Réanimation, 21, 20-26. https://doi.org/10.1016/S0750-7658(01)00555-X

[12] N'diaye, P.I., et al. (2013) The Transverse Abdominal Plane Block (TAP Block): Prospective Study in Children at the CHU A Le Dantec in Dakar. RAMUR Tome, 18, 30-34.

[13] Adnet, P. and Chobli, M. (1999) Practice of Anesthetics in Sub-Saharan Africa. Annales Françaises d' Anesthésie et de Réanimation, 18, 636-641. https://doi.org/10.1016/S0750-7658(99)80150-6

[14] Binan, F., Lemondeley, P., Blatt, A. and Arvis, T. (1999) Anesthetic Practices in Yaoundé (Cameroon). Annales Françaises d Anesthésie et de Réanimation, 18, 647-656. https://doi.org/10.1016/S0750-7658(99)80152-X

[15] Saissy, J.M. and Carpentier, J.P. (1996) Anesthesia in Developing Countries. In: Kamran, S., Ed., Surgical Anesthesia-Resuscitation, Flammarion Médecine-Sciences, Paris, 610-617.

[16] Clergue, F., et al. (1998) French Society of Anesthesia, Resuscitation: The Practice of Anesthesia in France in 1996. Anesthesiology, 91, 1509. https://pubs.asahq.org/anesthesiology/article/91/5/1509/39623/French-Survey-of-A nesthesia-in-1996

[17] Konan, J.E., et al. (2014) Anesthetic Activity in the Operating Room of the Yopougon University Hospital (Abidjan) during the Post-Electoral Armed Conflict in Côte d'Ivoire. https://web-saraf.net/Activite-anesthesique-au-bloc.html

[18] Essola, L., et al. (2013) Pediatric Anesthesia in an African Environment: Experience of a Gabonese Adult Hospital. 
https://web-saraf.net/Anesthesie-pediatrique-en-milieu.html

[19] Abbe, C.M., Binlin-Dadié, R., Ouattara, A., N'Guessan, Y.F., Tetchi, Y.D. and Brouh, Y. (2013) Delays for Anesthetic Management of Gynecological and Obstetrical Emergencies in The Teaching Hospital of Cocody at (Abidjan-Ivory Coast). RAMUR Tome, 18, 35-39. https://web-saraf.net/Delais-de-prise-en-charge.html

[20] Tiret, L., Desmons, J.M., Hatton, F. and Vourc'h, G. (1986) Complications Associated with Anaesthesia-Perspective Survey in France. Canadian Anaesthetists' Society Journal, 33, 336-344. https://doi.org/10.1007/BF03010747 